\title{
The effect of simulated erosive conditions on the frictional behavior of different orthodontic bracket-wire combinations
}

\section{Wpływ symulowanych warunków erozyjnych na charakterystykę cierną różnych kombinacji zamka i drutu ortodontycznego}

\author{
Tomasz Stefański ${ }^{1, A-F}$, Anna Kloc-Ptaszna ${ }^{2, B, C, E, F}$, Lidia Postek-Stefańska ${ }^{3, B-F}$ \\ 1 Department of Orthodontics, Medical University of Silesia, Zabrze, Poland \\ ${ }^{2}$ Institute of Engineering Materials and Biomaterials, Silesian University of Technology, Gliwice, Poland \\ ${ }^{3}$ Chair and Department of Pediatric Dentistry, Medical University of Silesia, Zabrze, Poland \\ A - research concept and design; $\mathrm{B}$ - collection and/or assembly of data; $\mathrm{C}$ - data analysis and interpretation; \\ $D$ - writing the article; $E$ - critical revision of the article; $F$ - final approval of the article
}

Address for correspondence

Tomasz Stefański

E-mail: tomasz.stefanski@sum.edu.pl

Funding sources

The study was supported by grants KNW-2-114/N/7/N and KNW-2-K02/N/8/K from the Polish Ministry of Science and Higher Education.

Conflict of interest

None declared

Received on January 19, 2019

Reviewed on March 9, 2019

Accepted on March 19, 2019

Published online on June 28, 2019

Cite as

Stefański T, Kloc-Ptaszna A, Postek-Stefańska L. The effect of simulated erosive conditions on the frictional behavior of different orthodontic bracket-wire combinations. DentMed Probl. 2019;56(2):173-177. doi:10.17219/dmp/105832

DOI

$10.17219 / \mathrm{dmp} / 105832$

Copyright

๑ 2019 by Wroclaw Medical University

This is an article distributed under the terms of the

Creative Commons Attribution 3.0 Unported License (CC BY 3.0)

(https://creativecommons.org/licenses/by/3.0/)

\begin{abstract}
Background. Frictional resistance is an important parameter in orthodontics that influences the effectiveness of archwire-guided tooth movement. Since the consumption of dietary acids has increased considerably over the last 2 decades, there is a rationale for investigating the process of degradation of orthodontic materials in an acidic environment and its effect on clinical efficiency.
\end{abstract}

Objectives. The aim of this study was to evaluate the effect of simulated erosive conditions on the frictional behavior between the brackets of 3 different materials and 3 different wire alloys.

Material and methods. Three types of twin orthodontic brackets (stainless steel (SS), monocrystalline ceramic and titanium) and 3 types of archwires of the same dimension (SS, nickel-titanium (Ni-Ti) and beta-titanium (titanium-molybdenum alloy - TMA) were tested in 9 different combinations under simulated erosive and non-erosive conditions (18 groups, $n=10$ ). Bracket-wire specimens in the erosive-condition groups were subjected to a pH cycling regimen with $1 \%$ citric acid and artificial saliva for 5 consecutive days. Bracket-wire specimens from the non-erosive-condition groups were incubated only in artificial saliva for 5 days. Static and kinetic friction were determined by measuring the force needed to move the wire through the bracket. A three-way analysis of variance and pairwise comparisons with the Student-Newman-Keuls test were performed.

Results. Irrespective of the conditions, SS brackets with SS wire demonstrated significantly lower mean static and kinetic frictional resistance than other bracket-wire combinations $(p<0.01)$. Ceramic and titanium brackets generated high frictional forces with all 3 types of wire tested. Erosive conditions did not significantly influence static and kinetic frictional resistance in all bracket-wire groups.

Conclusions. Erosive conditions do not affect the frictional behavior of SS, Ni-Ti and TMA orthodontic archwires at a clinically significant level.

Key words: friction, dental erosion, corrosion, orthodontic brackets, orthodontic archwires

Słowa kluczowe: tarcie, erozja zębów, korozja, zamki ortodontyczne, łuki ortodontyczne 


\section{Introduction}

The consumption of dietary acids has increased considerably over the last 2 decades, and is thought to be the main reason for dental erosion. ${ }^{1}$ Erosive tooth wear is becoming a growing problem particularly among adolescents and young adults, who make up a major portion of orthodontic patients. ${ }^{2}$ This emphasizes the need for investigating the process of degradation of orthodontic materials in an acidic environment both in terms of biocompatibility and clinical efficiency. In the literature, several studies have aimed to assess the effect of an acidic diet and soft drinks on the properties of orthodontic fixed appliances, including shear bond strength, ${ }^{3-6}$ corrosion resistance, ${ }^{7-10}$ metal ion release, ${ }^{11-14}$ surface microtopography, roughness, ${ }^{15}$ micro- and nanohardness, ${ }^{16}$ tensile strain, modulus of elasticity, yield strength, ${ }^{17}$ and color stability of orthodontic adhesives and elastic ligatures. ${ }^{18,19}$ Surprisingly, very few studies have focused on frictional resistance, which is a crucial clinical parameter that influences the effectiveness of arch guided tooth movement (sliding).

Friction can be defined as the resistance to movement when one object moves tangentially against another. ${ }^{20,21}$ In order to move a tooth using a conventional orthodontic fixed appliance, friction at the bracket-archwire interface has to be overcome. Numerous factors have been identified as influencing frictional resistance, such as archwire properties (material, cross-sectional shape or size, surface texture, stiffness), bracket properties (material, surface treatment, manufacturing process, slot dimension, bracket design, prescription), method of ligation, interbracket distance, and biological factors such as saliva (acquired pellicle), plaque, corrosion, mastication (oral forces), and temperature. $^{20-25}$

Considering the wide variety of orthodontic wire and bracket materials, it has been observed that their various combinations exhibit different frictional behavior. Ceramic brackets are known to produce considerably higher friction than stainless steel (SS) brackets. ${ }^{22}$ Archwires from nickeltitanium (Ni-Ti) and titanium-molybdenum (TMA) alloy demonstrate higher resistance to sliding than SS wires. ${ }^{24,25}$ As a major reason for the abovementioned difference, a surface chemical reactivity (titanium content) is proposed rather than surface topography (roughness). ${ }^{22}$

Although friction could be advantageous in some situations, e.g., for maintaining the anchorage or tooth movement in a closed-loop technique, high frictional forces decrease tooth sliding, thereby prolonging treatment time. ${ }^{21}$ Kusy and Whitley demonstrated that $12-60 \%$ of the applied orthodontic force is reduced by friction. ${ }^{22,23}$

The purpose of the present study was to assess the effect of the simulated erosive conditions on the resistance to sliding between brackets of 3 different materials (SS, ceramic and titanium) and 3 different wire alloys (SS, Ni-Ti and TMA).

\section{Material and methods}

\section{Study design}

The present study followed a 3 (bracket material) $\times 3$ (wire material) $\times 2$ (erosive/non-erosive condition) factorial design, hence 18 experimental groups were included, each of 10 specimens. The null hypothesis was that the tested bracket-wire combinations would not differ from each other under erosive and non-erosive conditions.

\section{Bracket-wire specimen preparation}

Three types of preadjusted edgewise maxillary premolar twin brackets with 0.022 slot were tested:

1) stainless steel (Omniarch ${ }^{\circledR}$; Dentsply GAC, York, USA, torque $-7^{\circ}$, angulation $0^{\circ}$ and distal offset $0^{\circ}$ );

2) monocrystalline ceramic (Inspire $I C E^{\circledR}$; Ormco, Glendora, California, USA, torque $-7^{\circ}$, angulation $0^{\circ}$, distal offset $0^{\circ}$ );

3) titanium (Titanium Orthos ${ }^{\circledR}$; Ormco, torque $-6^{\circ}$, angulation $0^{\circ}$, rotation $0^{\circ}$ ).

Each bracket was positioned and bonded on the SS hex nut with composite adhesive (Transbond XT Light Cure Adhesive; 3M, Maplewood, USA). Three types of orthodontic wire alloys of the same dimensions $(0.019 \times 0.025 \mathrm{inch})$ and from the same manufacturer (Ormco) were tested:

a) stainless steel (SS; chromium, 17-19\%, 8-10\% nickel);

b) nickel-titanium (Ni-Ti; $54.9 \%$ titanium, $45 \%$ nickel, $<1 \%$ other);

c) beta-titanium (TMA; 79\% titanium, 11\% molybdenum, $6 \%$ zinc, $4 \%$ tin).

The wires were cut into 25 -mm-long segments from the straight distal ends of the archwire and tied to the brackets using a 0.120-inch-diameter elastic ligature (Ormco). A total of 180 bracket-wire specimens were prepared.

\section{Erosive conditions}

A 1\% citric acid (Sigma Aldrich, St. Louis, USA) aqueous solution with a $\mathrm{pH}$ of 3.2 was used as the standard erosive solution. Bracket-wire specimens in erosive-condition groups were subjected to $\mathrm{pH}$-cycling. Specimens were exposed to the citric acid solution for $10 \mathrm{~min}$ ( $\mathrm{pH} \mathrm{3.2,10} \mathrm{mL/specimen,}$ at $21^{\circ} \mathrm{C}$ with slow stirring) and then immersed in artificial saliva for $60 \mathrm{~min}\left(\mathrm{pH} 6.8,10 \mathrm{~mL} /\right.$ specimen, at $36^{\circ} \mathrm{C}$ without stirring). This procedure was repeated 6 times a day over 5 consecutive days. During the remaining time, specimens were stored in artificial saliva. One liter of artificial saliva contained: $2.7 \mathrm{~g}$ porcine gastric mucin, $1.27 \mathrm{~g} \mathrm{KCl}, 0.580 \mathrm{~g} \mathrm{NaCl}, 0.330$ g, $0.34 \mathrm{Na}_{2} \mathrm{HPO}_{4}, 0.20$ urea $\mathrm{KH}_{2} \mathrm{PO}_{4}, 0.17 \mathrm{~g} \mathrm{CaCl}_{2} \mathrm{x} 2 \mathrm{H}_{2} \mathrm{O}, 0.16$ g NH $4 \mathrm{Cl}, 0.16 \mathrm{~g}$ $\mathrm{NaSCN}, 0.03$ g glucose, and $0.002 \mathrm{~g}$ ascorbic acid. The $\mathrm{pH}$ was adjusted to 6.8 by titrating a phosphate buffer to the solution. ${ }^{26}$ The total time of erosion in the experiment was $5 \mathrm{~h}(6 \times 10 \mathrm{~min} \times 5$ days $)$. Bracket-wire specimens 
from non-erosive-condition groups were only in artificial saliva for 5 days. All the solutions were renewed daily. Specimens were incubated collectively in a square-shaped Lock\&Lock plastic container.

\section{Friction testing}

Before the friction test, each specimen was washed with distilled water. The hex nuts with bracket-wire assemblies were fixed on the bolt rod perpendicularly relative to the ground in a vertical motorized testing machine (MX2; Imada, Toyohashi, Japan) equipped with a $50 \mathrm{~N}$ load cell (ZP, Imada). A schematic diagram of the testing apparatus is shown in Fig. 1. The wire end was attached to the upper grip of the testing unit. The force needed to move the wire through the bracket at a crosshead speed of $10 \mathrm{~mm} / \mathrm{min}$ over a $5-\mathrm{mm}$ length of the wire was recorded continuously. Data was obtained using a computer program (ZP Recorder; Data Acquisition Software, Imada). Static friction was set as the maximum value at the beginning of movement on the force-displacement graphs. The kinetic friction was calculated as the mean of the frictional force measured after static peak at $0.5 \mathrm{~mm}, 1.0 \mathrm{~mm}$, $2.0 \mathrm{~mm}, 3.0 \mathrm{~mm}, 4.0 \mathrm{~mm}$, and $5.0 \mathrm{~mm}$ of displacement.

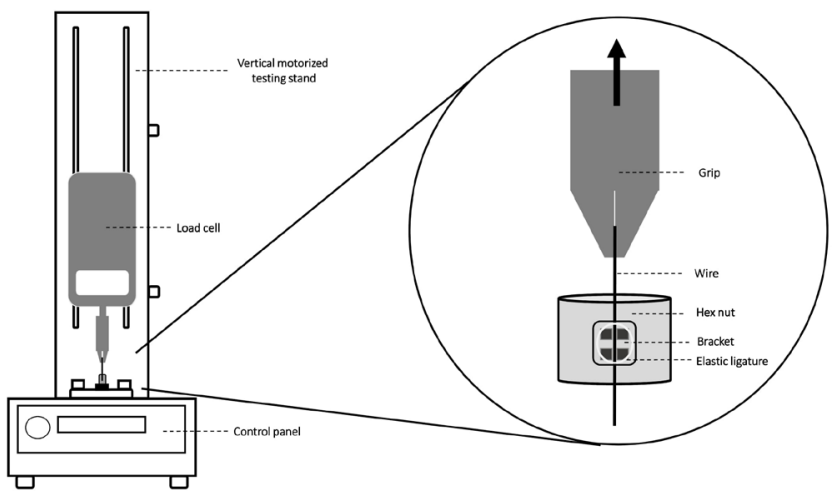

Fig. 1. Schematic diagram of testing apparatus and detailed view of bracket-archwire assembly
Each bracket/wire/ligature combination was tested once in a passive angulation (less than the critical contact angle) at a room temperature of $23^{\circ} \mathrm{C}$ in a dry state. New elastic ligature was placed immediately prior each test run to avoid variability in the ligature relaxation rate. All test assemblies and measurements were made by 1 operator.

\section{Statistical analysis}

Descriptive statistics including the mean and standard deviation $(S D)$ values were calculated for each bracketarchwire combination. A three-way analysis of variance (ANOVA) was used to evaluate the effects of bracket type (metallic, monocrystalline or titanium), wire type (SS, Ni-Ti or TMA) and condition (erosive or non-erosive) on frictional resistance. Pairwise comparisons were performed using the Student-Newman-Keuls post-hoc test. The level of significance was set at $p=0.05$. Statistical analysis was performed with STATISTICA v. 8.0 software (StatSoft, Tulsa, USA)

\section{Results}

Mean static and kinetic frictional forces between the tested brackets and wires after erosive and non-erosive conditions are shown in Table 1. Post hoc pairwise comparisons revealed that, irrespective of the conditions, SS brackets with SS wire demonstrated significantly lower static and kinetic frictional resistance than other bracket-wire combinations $(p<0.01)$. With metallic brackets the highest friction demonstrated was the TMA wire, followed by Ni-Ti (Fig. 2). Ceramic and titanium brackets generated higher frictional forces with all 3 types of wires tested. Erosive conditions did not significantly influence static and kinetic frictional forces in all bracket-wires groups. Therefore, the null hypothesis should be retained.

Table 1. Means $\pm S D$ of static and kinetic friction $[\mathrm{N}]$ between the tested brackets and wires under erosive and non-erosive conditions. Means sharing the same superscript letter within columns do not differ significantly $(p>0.05)$

\begin{tabular}{|c|c|c|c|c|c|c|c|}
\hline \multirow{3}{*}{ Bracket } & \multirow{3}{*}{ Wire } & \multicolumn{4}{|c|}{ Condition } & \multirow{3}{*}{$\begin{array}{c}p \text {-value } \\
\text { (static friction) }\end{array}$} & \multirow{3}{*}{$\begin{array}{c}p \text {-value } \\
\text { (kinetic friction) }\end{array}$} \\
\hline & & \multicolumn{2}{|c|}{ Non-erosive } & \multicolumn{2}{|c|}{ Erosive } & & \\
\hline & & static friction & kinetic friction & static friction & kinetic friction & & \\
\hline Metallic & SS & $1.21 \pm 0.79^{A}$ & $1.02 \pm 0.63^{\mathrm{A}}$ & $1.68 \pm 1.13^{\mathrm{A}}$ & $1.51 \pm 0.80^{A}$ & 0.11 & 0.09 \\
\hline Metallic & $\mathrm{Ni}-\mathrm{Ti}$ & $2.89 \pm 0.83^{B}$ & $2.31 \pm 0.82^{\mathrm{B}}$ & $2.72 \pm 0.71^{B}$ & $2.27 \pm 0.77^{B}$ & 0.89 & 0.71 \\
\hline Metallic & TMA & $4.15 \pm 0.92^{c}$ & $3.47 \pm 0.74^{c}$ & $4.13 \pm 1.25^{c}$ & $3.57 \pm .1 .01^{c}$ & 0.90 & 0.87 \\
\hline Ceramic & SS & $4.47 \pm 1.09 c$ & $4.02 \pm 1.21^{C}$ & $4.89 \pm 1.34^{c}$ & $4.27 \pm 1.34^{C}$ & 0.84 & 0.46 \\
\hline Ceramic & $\mathrm{Ni}-\mathrm{Ti}$ & $4.93 \pm 0.99 c$ & $4.58 \pm 0.67^{c}$ & $4.55 \pm 1.14^{C}$ & $4.21 \pm 0.89^{c}$ & 0.58 & 0.50 \\
\hline Ceramic & TMA & $4.84 \pm 1.15^{c}$ & $4.04 \pm 1.10^{c}$ & $3.99 \pm 1.26^{c}$ & $3.67 \pm 1.14^{c}$ & 0.11 & 0.27 \\
\hline Titanium & SS & $3.82 \pm 1.02^{c}$ & $3.62 \pm 0.96^{B}$ & $3.57 \pm 0.99^{c}$ & $2.99 \pm 1.26^{C}$ & 0.79 & 0.22 \\
\hline Titanium & $\mathrm{Ni}-\mathrm{Ti}$ & $4.69 \pm 0.84^{c}$ & $3.91 \pm 0.60^{c}$ & $4.42 \pm 1.19 c$ & $3.66 \pm 0.93^{c}$ & 0.41 & 0.44 \\
\hline Titanium & TMA & $4.52 \pm 1.11^{C}$ & $4.04 \pm 0.97^{c}$ & $4.69 \pm 0.99^{c}$ & $3.42 \pm 0.73^{C}$ & 0.88 & 0.42 \\
\hline
\end{tabular}

SD - standard deviation; TMA - beta-titanium; Ni-Ti - nickel-titanium; SS - stainless steel. 

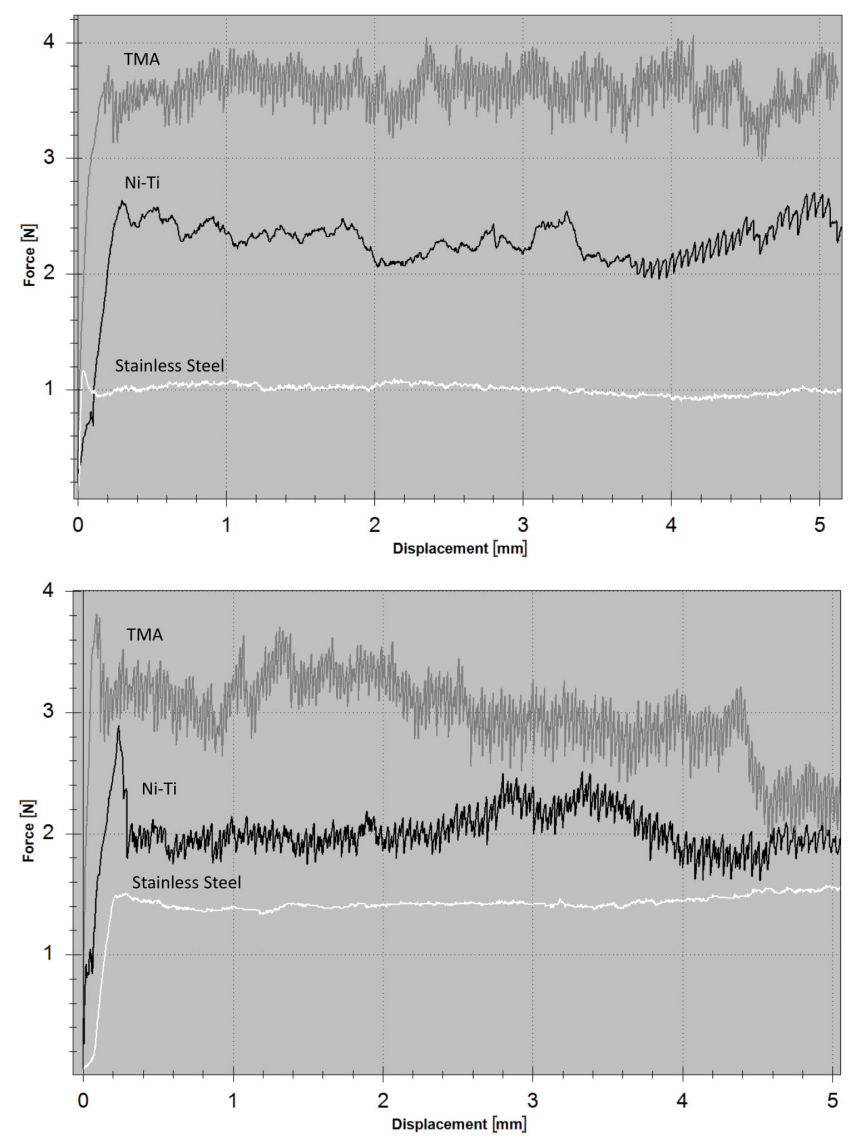

Fig. 2. A. Diagram of the frictional forces produced by randomly chosen specimens of stainless steel, Ni-Ti and TMA orthodontic wires with metallic bracket in the non-erosion group. B. Diagram of the frictional forces produced by randomly chosen specimens of stainless steel, Ni-Ti and TMA orthodontic wires with metallic bracket in the erosion group

\section{Discussion}

The present study was designed to differentiate static and kinetic friction between different brackets and wires under erosive and non-erosive conditions. While the static friction is the smallest force needed to start the motion, the kinetic frictional force resists the sliding during a movement. Static friction seems to be more clinically relevant since orthodontic tooth movement is not continuous, ${ }^{21}$ but involves repeated tipping and uprighting. In the present study, single bracket-wire assemblies were compared to minimize the possible variability of normal forces that can be present in multiple bracket-wire interfaces.

Under normal conditions, SS archwire had the lowest frictional forces, while Ni-Ti and TMA exhibited significantly higher friction. This observation confirms previous results. ${ }^{23-25}$ To date, only 2 studies evaluating the frictional behavior of orthodontic archwires under erosive conditions have been published; however, none of them have investigated this effect under a simulated $\mathrm{pH}$-cycling environment using conventional metallic brackets and 3 different archwire materials. Jaber et al. assessed the effects of cariogenic and erosive challenges (citric acid,
pH 2.3, 60 min for 21 days) on copper-nickel-titanium (CuNiTi) wires by determining the surface roughness of the wires and friction between the wires and passive self-ligating brackets. It was observed that although surface roughness was greater after erosive challenges, the friction did not increase. ${ }^{15}$ Nanjundan and Vimala ${ }^{27}$ studied surface morphology and frictional forces between SS wire and metallic and polycrystalline alumina brackets after exposure to various erosive solutions (Pepsi, vinegar) and an acidulated fluoride prophylactic agent. They demonstrated higher static and kinetic frictional forces in the Pepsi group and the greatest surface roughness. ${ }^{27}$ However, the limitation of the latter study is that it was conducted after continuous 24-hour exposure to the acidic solution, whereas intraoral $\mathrm{pH}$ levels rather oscillate than remain constant.

It should also be noted that archwires may exhibit various corrosion susceptibility and metal ion release due to different manufacturing processes. ${ }^{7}$ An acidic oral environment can increase susceptibility to corrosion and breakdown failure of Ni-Ti alloys due to hydrogen absorption. ${ }^{28}$ This process can be accelerated in the presence of fluoride, as the hydrofluoric acid (HF) disrupts the protective $\mathrm{TiO}_{2}$ passive oxide surface film. ${ }^{29}$ Moreover, Harris et al. showed decreased tensile strain, modulus of elasticity and yield strength in an acidified simulated oral environment. ${ }^{17}$ The surface corrosion of archwire may influence the friction at the bracket-archwire-ligature interface unit, impeding the free sliding action.

Classical frictional force (F) is directly proportional to the force applied by ligation $(\mathrm{N})$ and the coefficient of friction $(\mu)$, which depends on the archwire and bracket surface roughness: $\mathrm{F}=\mu \mathrm{N} .{ }^{20}$ However, the relation between friction and surface roughness is still the subject of controversy. Some studies did not support such a relationship. $7,15,22,30-33$ It should be noted that clinically, when a tooth (bracket) slides on the arch, the edges of the slot may contact the archwire, leading to its binding. Kusy and Whitley ${ }^{23}$ have estimated the critical contact angle $(\theta)$ between archwire and bracket to be $3.7^{\circ}$, below which the configuration is passive and above which binding occurs (active configuration). At greater angle values, the slot edges may permanently deform the archwire, causing notching. With a $7^{\circ}$ angulation, the binding produces $80 \%$ of the resistance to sliding. ${ }^{33}$ It is important to highlight that in the present study only classical friction was measured, not taking into account the 2 other components of the resistance to sliding (binding and notching).

\section{Conclusions}

In conclusion, the findings from the present study indicate that erosive conditions do not affect the frictional behavior of SS, Ni-Ti and TMA orthodontic archwire at clinically significant levels. 


\section{ORCID iDs}

Tomasz Stefański (iD https://orcid.org/0000-0002-8133-2845

Anna Kloc-Ptaszna (i) https://orcid.org/0000-0001-7647-9773

Lidia Postek-Stefańska (D) https://orcid.org/0000-0002-6573-019X

\section{References}

1. Lussi A, Megert B, Shellis RP, Wang X. Analysis of the erosive effect of different dietary substances and medications. Br J Nutr. 2012;107(2):252-262.

2. Bartlett DW, Lussi A, West NX, Bouchard P, Sanz M, Burgeois D. Prevalence of tooth wear on buccal and lingual surfaces and possible risk factors in young European adults. J Dent. 2013;41(11):1007-1013.

3. Oncag G, Tuncer AV, Tosun YS. Acidic soft drinks effects on the shear bond strength of orthodontic brackets and a scanning electron microscopy evaluation of the enamel. Angle Orthod. 2005;75(2):247-253.

4. Hammad SM, Enan ET. In vivo effects of two acidic soft drinks on shear bond strength of metal orthodontic brackets with and without resin infiltration treatment. Angle Orthod. 2013;83(4):648-652.

5. Medeiros MID, Carlo HL, Santos RLD, et al. TiF4 varnish protects the retention of brackets to enamel after in vitro mild erosive challenge. J Appl Oral Sci. 2018;26:e20170222.

6. Shahabi M, Jahanbin A, Esmaily H, Sharifi H, Salari S. Comparison of some dietary habits on corrosion behavior of stainless steel brackets: An in vitro study. J Clin Pediatr Dent. 2011;35(4):429-432.

7. Huang $\mathrm{HH}$. Surface characterization and corrosion resistance of nickel-titanium orthodontic archwire in artificial saliva of various degrees of acidity. J Biomed Mater Res A. 2005;74(4):629-639.

8. Huang $\mathrm{HH}$. Corrosion resistance of stressed $\mathrm{NiTi}$ and stainless steel orthodontic wires in acid artificial saliva. J Biomed Mater Res A. 2003;66(4):829-839.

9. Benyahia H, Ebntouhami M, Forsal I, Zaoui F, Aalloula E. Corrosion resistance of $\mathrm{NiTi}$ in fluoride and acid environments. Int Orthod. 2009;7(4):322-334.

10. Holla AK, Kumar S, Mogra S, Shetty SV, Urala A, Prasad MB. Evaluation of the breakdown potential of orthodontic archwire in acidic soft drinks. J Ind Orthod Soc. 2012;46(4):238-244.

11. Huang $\mathrm{HH}$, Chiu $\mathrm{TH}$, Lee $\mathrm{TH}$, et al. Ion release from NiTi orthodontic wires in artificial saliva with various acidities. Biomaterials. 2003;24(20):3585-3592.

12. Mikulewicz M, Wołowiec P, Loster BW, Chojnacka K. Do soft drinks affect metal ions release from orthodontic appliances? J Trace Elem Med Biol. 2015;31:74-77.

13. Wołowiec P, Chojnacka K, Loster BW, Mikulewicz M. Do dietary habits influence trace elements release from fixed orthodontic appliances? Biol Trace Elem Res. 2017;180(2):214-222.

14. Kuhta M, Pavlin D, Slaj M, Varga S, Lapter-Varga M, Slaj M. Type of archwire and level of acidity: Effects on the release of metal ions from orthodontic appliances. Angle Orthod. 2009;79(1):102-110.

15. Jaber LCL, Rodrigues JA, Amaral FLB, França FMG, Basting RT, Turssi CP. Degradation of orthodontic wires under simulated cariogenic and erosive conditions. Braz Oral Res. 2014;28(1):1-6.

16. Parenti SI, Guicciardi S, Melandri C, et al. Effect of soft drinks on the physical and chemical features of nickel-titanium-based orthodontic wires. Acta Odontol Scand. 2012;70(1):49-55.

17. Harris EF, Newman SM, Nicholson JA. Nitinol arch wire in a simulated oral environment: Changes in mechanical properties. Am J Orthod Dentofacial Orthop. 1988;93(6):508-513.

18. Fernandes AB, Riberio AA, Araujo MV, Ruellas AC. Influence of exogenous pigmentation on the optical properties of orthodontic elastic ligatures. J Appl Oral Sci. 2012;20(4):462-466.

19. Faltermeier A, Rosentrit M, Reicheneder C, Behr M. Discolouration of orthodontic adhesives caused by food dyes and ultraviolet light. Eur J Orthod. 2008;30(1):89-93.

20. Rossouw PE. Friction: An overview. Semin Orthod. 2003;9(4):218-222.

21. Burrow SJ. Friction and resistance to sliding in orthodontics: A critical review. Am J Orthod Dentofacial Orthop. 2009;135(4):442-447.

22. Kusy RP, Whitley JQ. Friction between different wire-bracket configurations and materials. Semin Orthod. 1997;3(3):166-177.
23. Kusy RP, Whitley JQ. Influence of archwire and bracket dimensions on sliding mechanics: Derivations and determinations of the critical contact angles for binding. Eur J Orthod. 1999;21(2):199-208.

24. Kapila S, Angolkar PV, Duncanson MG Jr, Nanda RS. Evaluation of friction between edgewise stainless steel brackets and orthdontic wires of four alloys. Am J Orthod Dentofacial Orthop. 1990;98(2):117-126.

25. Angolkar PV, Kapila S, Duncanson MG Jr, Nanda RS. Evaluation of friction between ceramic brackets and orthodontic wires of four alloys. Am J Orthod Dentofacial Orthop. 1990;98(6):499-506.

26. Klimek J, Hellwig $\mathrm{E}$, Ahrens $\mathrm{G}$. Fluoride taken up by plaque, by the underlying enamel and by clean enamel from three fluoride compounds in vitro. Caries Res. 1982;16(2):156-161.

27. Nanjundan K, Vimala G. Evaluation of frictional resistance and surface characteristics after immersion of orthodontic brackets and wire in different chemical solutions: A comparative in vitro study. Indian J Dent Res. 2016;27(5):513-520.

28. Yokoyama K, Kaneko K, Moriyama K, Asaoka K, Sakai J, Nagumo M. Hydrogen embrittlement of $\mathrm{Ni}-\mathrm{Ti}$ supereleastic alloy in fluoride solution. J Biomed Mater Res A. 2003;65(2):182-187.

29. Kwon YH, Cheon YD, Seol HJ, Lee JH, Kim HI. Changes on NiTi orthodontic wires due to acidic fluoride solution. Dent Mater J. 2004;23(4):557-565.

30. Husmann $P$, Bourauel $C$, Wessinger $M$, Jäger $A$. The frictional behavior of coated guiding archwire. J Orofac Orthop. 2002;63(3):199-211.

31. Bourauel C, Fries T, Drescher D, Plietsch R. Surface roughness of orthodontic wires via atomic force microscopy, laser specular reflectance and profilometry. Eur J Orhtod. 1998;20(1):79-92.

32. Wichelhaus A, Geserick M, Hibst R, Sander FG. The effect of surface treatment and clinical use on friction in NiTi orthodontic wires. Dent Mater. 2005;21(10):938-945.

33. Articolo LC, Kusy RP. Influence of angulation on the resistance to sliding in fixed appliances. Am J Orthod Dentofacial Orthop. 1999;115(1):39-51. 
